\title{
MECHANICAL PROPERTIES OF CORONARY VEIN - IN VITRO EVALUATION OF LONGITUDINAL AND TRANSVERSAL SAMPLES
}

\author{
Tibor Balázs ${ }^{1}$, Eszter Bognár ${ }^{1}$, Endre Zima² János Dobránszky $^{3}$ \\ ${ }^{1}$ Budapest University of Technology and Economics (BUTE), Department \\ of Materials Science and Engineering \\ ${ }^{2}$ Semmelweis University, Cardiovascular Clinic \\ ${ }^{3}$ Research Group for Metals Technology of the HAS and BUTE, \\ Department of Materials Science and Engineering \\ balazs.tibor@freemail.hu
}

\begin{abstract}
Aims: Even though several publications are available and experiments were done in the topic of the mechanical properties of vessels there is no data for special veins like coronary veins. Previously a few rectangular coronary vein parts had been examined and the results show that probably there is a difference between the transversal and longitudinal direction of coronary vein. The aim of this study is to investigating the differences in the mechanical properties of the two directions with in vitro tensile tests.
\end{abstract}

Method: Coronary veins from six pig hearts were tested within one hour after explantation. Five transversal and nine longitudinal coronary vein samples were prepared from these hearts and kept in physiologic solution until the tests. The samples were evaluated in $37^{\circ} \mathrm{C}$ physiologic solution with tensile equipment and the force-displacement curves were recorded. Based on these curves and the tearing results the longitudinal and transversal tensile strengths, relative extensions and Young's modulus were calculated.

Results: The evaluation squarely proved the differences of mechanical properties between the longitudinal and transversal directions of coronary vein samples. Transversal direction had higher elongation properties $(248 \pm 117 \%$ vs. $137 \pm 37 \%)$ but lower resistance to mechanical loading $(0.99 \pm 0.16 \mathrm{MPa}$ vs. $2.55 \pm 0.46 \mathrm{MPa})$ than the longitudinal direction.

Conclusion: The experiments are successfully investigated the mechanical differences of coronary vein directions. These are important parameters, because in case of special application the maximal elongation capability and the maximal force that the vein can tolerate without injury had to be known. With the result of these experiments the maximal loading concerning to coronary veins can be modelled. However there are still question to answer for example the individual role of the different layers of coronary veins which is not known during the mechanical testing. Further investigations are necessary to perform in order to have a complete analysis of mechanical properties of coronary veins.

Keywords: coronary vein; mechanical properties; in vitro testing 


\section{Introduction}

Recently a new kind of in vitro testing of coronary vein was published (Balázs et al., 2008) with limitations and raised questions regarding to the method. It was necessary to carry out because the previously performed vessel examinations tested only saphenous veins and arteries from different areas of the body. The literature of mechanical properties of blood vessels are quite large and it is already known that the arteries can be modelled as two-layer model (Holzapfel GA et al., 2000; Holzapfel GA et al., 2002; Matsumoto T et al., 2002) and also founded that blood vessels have incremental Young's modulus even if they were investigated both for laws of elasticity and laws of viscoelasticity (Xiao Lu et al., 2004; Fung YC et al. 1995). It is also well known that the wall thickness and isobaric elastic properties of vein grafts increase after a few days and rearrangement of the elastic structures occurs (Monos E et al. 1995; Jenny S et al., 2006).

It is not enough to have experimental results for arteries from all over the body because the structural differences between arteries and veins cause differences in the mechanical properties as well. It is well known that the vein has three layers. The first is a strong outer cover of the vessel and consists of connective tissues, collagen and elastic fibres. The second one is the middle layer and consisting smooth muscle and elastic fibres, which is thinner in veins. The third one is consists of smooth endothelial cells. These three layers have three different mechanical properties and three different behaviours under mechanical loading.

Monos and his colleagues investigated the elastic modulus of different veins based on the Laplace-Frank equation (Monos E 2004). They used intravascular pressure to measure the tangential elastic stress and the relative displacement.
There are some similar investigations that concentrate on the blood flow simulation of the vessel systems (Molnár F et al. 2005; Till S et al., 2004; Till S et al., 2004) but these don't focus on mechanical properties on the complete modelling of blood circuit in arteries and veins as well.

Large coronary veins are placed on the outer surface of the heart between fat and pectoral muscle and the elongation mainly possible via diameter increasing. This suggests that the mechanical properties of longitudinal and transversal direction of coronary veins could be different.

In certain developments the initial data should be the mechanical properties of coronary veins such as the development of left ventricular pacemaker leads or electrophysiology diagnostic catheters that are placed in the coronary vein. From the view of electrophysiology and pacemaker lead fixation mechanisms, it is more important to know the maximal force and stress that may cause coronary vein dissections. This maximal force can be determined by tensile tests. The force required to tear a material and the amount it extends before tearing are point of interest. Typically, the testing involves taking a small sample with a fixed cross-section area, and then pulling it with a controlled, gradually increasing force until the sample changes shape or breaks. Analysis of force-displacement or strength-relative strain curves can convey much about the material being tested, and it can help in predicting it's behaviour.

The aim of this investigation is to evaluate the differences between the mechanical properties of transversal and longitudinal directions of coronary veins with in vitro tensile tests. 


\section{Methods}

Six pig hearts were received from slaughterhouse and had been delivered within one hour after explantation to the Semmelweis University in physiologic solution (Baxter Viaflo, Natrium Clorid 0,9\% "Bieffe" infusion). Coronary veins were prepared form these hearts immediately after receiving from slaughterhouse and kept in a physiologic solution until testing. The total time between explantation and testing phase was less than two hours.

Bartels-Stringer $\mathrm{M}$ et al suggest that after 3 hour storage in physiologic solution and normal saline solution, contractile and relaxant vascular responses are similar in isolated saphenous veins (Bartels-Stringer $\mathrm{M}$ et al., 2004 and Boerboom LE et al., 1992) proved that cold storage for $24 \mathrm{~h}$ did not affect vascular reactivity of blood vessels.

The diameters of coronary sinus (CS) were between 4 and $5 \mathrm{~mm}$. Longitudinal and transversal samples were prepared. Optimal size would be $5 \mathrm{~mm}$ width and $10 \mathrm{~mm}$ length without side branches. Finally 9 longitudinal and 5 transversal CS sample were prepared and stored in a physiologic solution until the testing. The length, width and thickness of prepared samples were measured immediately after preparation and recorded together the calculated cross sections (Table 1).

The longitudinal direction was defined as the longitudinal plane of the vein and the transversal direction was perpendicular to this, the plane of crosssection (Figure 1).

\begin{tabular}{|c|c|c|c|c|c|c|c|c|}
\hline \multirow[b]{2}{*}{ Sample } & \multicolumn{4}{|c|}{ Transversal samples } & \multicolumn{4}{|c|}{ Longitudinal samples } \\
\hline & $\begin{array}{c}\text { Width } \\
a_{t}(\mathrm{~mm})\end{array}$ & $\begin{array}{c}\text { Thickness } \\
\mathrm{h}_{\mathrm{t}}(\mathrm{mm})\end{array}$ & $\begin{array}{l}\text { Length } \\
1_{t}(\mathrm{~mm})\end{array}$ & $\begin{array}{c}\text { Cross } \\
\text { section } \\
\mathbf{A}_{0 \mathrm{t}}\left(\mathrm{mm}^{2}\right)\end{array}$ & $\begin{array}{c}\text { Width } \\
\mathrm{a}_{1}(\mathrm{~mm})\end{array}$ & $\begin{array}{c}\text { Thickness } \\
\mathrm{h}_{1}(\mathrm{~mm})\end{array}$ & $\begin{array}{l}\text { Length } \\
l_{1}(\mathrm{~mm})\end{array}$ & $\begin{array}{c}\text { Cross } \\
\text { section } \\
\mathbf{A}_{01}\left(\mathrm{~mm}^{2}\right)\end{array}$ \\
\hline 1 & 6.30 & 0.55 & 9.87 & 3.47 & 6.60 & 0.38 & 22.53 & 2.49 \\
\hline 2 & 6.10 & 0.48 & 9.97 & 2.91 & 8.83 & 0.34 & 17.87 & 2.97 \\
\hline 3 & 6.37 & 0.47 & 10.87 & 2.97 & 8.10 & 0.40 & 18.53 & 3.21 \\
\hline 4 & 6.70 & 0.52 & 7.97 & 3.48 & 6.80 & 0.40 & 16.10 & 2.74 \\
\hline 5 & 5.90 & 0.40 & 8.93 & 2.36 & 7.73 & 0.53 & 22.30 & 4.10 \\
\hline 6 & - & - & - & - & 6.77 & 0.42 & 23.53 & 2.84 \\
\hline 7 & - & - & - & - & 7.83 & 0.48 & 19.07 & 3.76 \\
\hline 8 & - & - & - & - & 9.03 & 0.48 & 17.70 & 4.37 \\
\hline 9 & - & - & - & - & 8.93 & 0.43 & 15.77 & 3.87 \\
\hline Mean \pm CI & $6.27 \pm 0.35$ & $0.48 \pm 0.06$ & $9.52 \pm 1.30$ & $3.04 \pm 0.47$ & $7.85 \pm 0.80$ & $0.43 \pm 0.05$ & $19.27 \pm 2.38$ & $3.37 \pm 0.55$ \\
\hline
\end{tabular}

Table 1. Width, thickness, lengths and cross sections of the rectangular vein samples

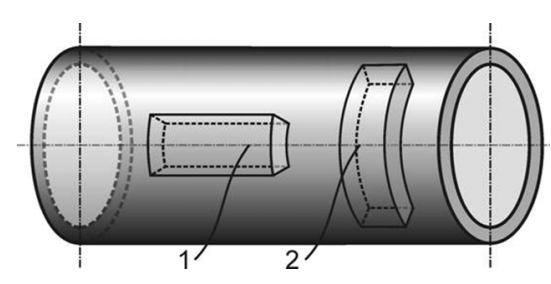

Figure 1. Definition of sample directions (1: longitudinal; 2: transversal)
The tensile tests were performed at Budapest University of Technology and Economics, Faculty of Mechanical Engineering, Department of Polymer Engineering with Zwick Z020 tensile test machine.

A new type of grip was developed, because the previously applied grips and fixation modes caused the sample rupture just after fixation. Two different types of surfaces were used in 


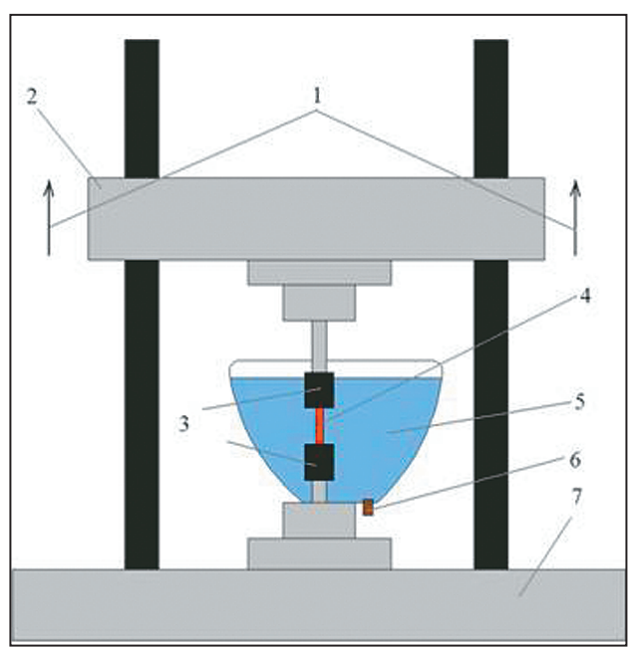

Figure 2. Testing equipment:

1- direction of tensile force; 2 - upper clamp;

3 - grips; 4 - vein sample; 5 - physiologic solution on $37^{\circ} \mathrm{C} ; 6$ - plug; 7 - lower clamp

one grip for fixating the coronary vein parts, one side was silicone and the opposite was reticulated metal. This combination of materials was appropriate and the fixation was stable.

A $37{ }^{\circ} \mathrm{C}$ degree physiologic solution (Baxter Viaflo, Natrium Clorid 0,9\% "Bieffe" infusion) was used (Figure 2) to modelling the original surround and after every single testing phase it was drained via the plug and replaced with new $37^{\circ} \mathrm{C}$ degree physiologic solution.

Tearing tests were performed with fixed lower camp and a moving upper camp with a constant stretching speed about $20 \mathrm{~mm} / \mathrm{min}$. The distance between the grips was $5 \mathrm{~mm}$ in case of the longitudinal samples and it had to be decreased because of size limits to $3 \mathrm{~mm}$ for the transversal samples. These distances were used as the starting length $\left(\mathrm{L}_{0}\right)$ for the relative extension calculations.

Maximal force and the inherent travel distance values from the recorded force in function of displacement curves were used as initial values of the calculations (Table 2).

Relative extension as it shown in Equation 1 is the percentage of elongation during the tensile test. It was calculated as the ratio of the starting distance and the displacement.

$\varepsilon=\frac{\Delta L}{L_{0}} \cdot 100 \%$

Where is $\varepsilon$-relative extension, $\mathrm{L}_{0}$ - starting length, $\Delta \mathrm{L}-$ displacement (recorded by the test machine during test).

\begin{tabular}{|c|c|c|c|c|}
\hline \multirow[b]{2}{*}{ Sample } & \multicolumn{2}{|c|}{ Transversal } & \multicolumn{2}{|c|}{ Longitudinal } \\
\hline & $\begin{array}{c}\text { Displacement } \\
\Delta \mathbf{L}_{\mathrm{t}}(\mathrm{mm})\end{array}$ & $\begin{array}{c}\text { Maximal force } \\
\mathrm{F}_{\text {tmax }}(\mathrm{N})\end{array}$ & $\begin{array}{c}\text { Displacement } \\
\Delta \mathrm{L}_{1}(\mathrm{~mm})\end{array}$ & $\begin{array}{l}\text { Maximal force } \\
F_{\text {lmax }}(N)\end{array}$ \\
\hline 1 & 11.16 & 3.76 & 6.25 & 5.94 \\
\hline 2 & 4.22 & 3.19 & 7.31 & 7.05 \\
\hline 3 & 11.03 & 3.29 & 5.84 & 9.54 \\
\hline 4 & 6.95 & 3.39 & 7.60 & 4.94 \\
\hline 5 & 3.90 & 1.68 & 10.06 & 9.50 \\
\hline 6 & - & - & 4.57 & 8.66 \\
\hline 7 & - & - & 6.33 & 11.68 \\
\hline 8 & - & - & 9.10 & 9.27 \\
\hline 9 & - & - & 7.37 & 11.18 \\
\hline Mean \pm CI & $7.45 \pm 4.17$ & $3.06 \pm 0.95$ & $7.16 \pm 1.4$ & $8.64 \pm 1.89$ \\
\hline
\end{tabular}

Table 2. Travel distance and maximal force values for longitudinal and transversal samples based on the force-displacement curves 
Typically the cross section at the time of rupture is necessary to define the tensile strength. In case of veins only the starting cross section was available because after tearing the necessary sizes at the time of rupture couldn't be measured. To evaluate the maximal strengths (tensile strength as it is shown in Equation 2) can be tolerated by the veins, the recorded maximal forces and the previously calculated original cross section was used.

$\sigma=\frac{F_{m}}{A_{0}}$

Where is $\sigma$ - tensile strength, $\mathrm{F}_{\text {max }}$ - maximal force (recorded by the test machine during test), $\mathrm{A}_{0}$ - original cross section.

To evaluate the elastic properties it was important to measure the degree of the elastic deformation of veins under loading. Based on the tensile strength and relative extension, the Young's modulus (elastic modulus) of the coronary veins had been estimated with Equation 3.

$E=\frac{\sigma}{\varepsilon}$

Where is E - Elastic modulus, $\sigma$ - tensile strength, $\varepsilon$ - relative extension.

Each prepared coronary sinus sample was successfully evaluated. The fixation mode was proved to be stable however the first transversal sample seemed to be instable. The force displacement curves were recorded and the tensile strength in function of relative extension curves were made based on the previously defined equations for the transversal and longitudinal directions of coronary veins.

\section{Results}

Tensile strength in function of relative extension curves for the longitudinal samples were prepared (Figure 3).
The initial parts of the curves were identical, showing the same elastic properties. On the curves of the 1, 4 and the 9 samples there were notches which could be connected to the partional tearing of fat tissue which can not be elongate as much the vein layers can. Except these three curves, the others had continuous running-up, elastic phase until the maximum forces and the maximal tensile strengths were reached. At the point of the maximum loading the veins had the first injury and after that a fast dive was observed in all of the cases. The reason was the damage of the strongest layer and a much lower force was needed to keep the elongation.

As the vein consists of three layers and fat tissue on the surface, after a certain elongation only the tearing force of fat tissue was recorded. These parts were removed from the curves in Figure 3.

Testing of transversal samples was much more complicated because of the smaller sizes. Different curves of the samples were received (Figure 4), basically two types were represented. The first type what could be connected to the 2. and 5. samples was similar to the longitudinal curve characteristic. The others had different running up phases with slower increasing of the strength. Injury of the vein happened at the peak of the curves where is the maximal loading and the end of the elastic phase. Slow decreasing trend was observed in the loading force and strength after the damage caused by the maximal load.

Based on the recorded curves and the defined equations the relative extension, tensile strength and elastic modulus of the coronary veins were calculated and detailed in Table 3.

There are differences in the mechanical properties of the longitudinal and transversal sam- 


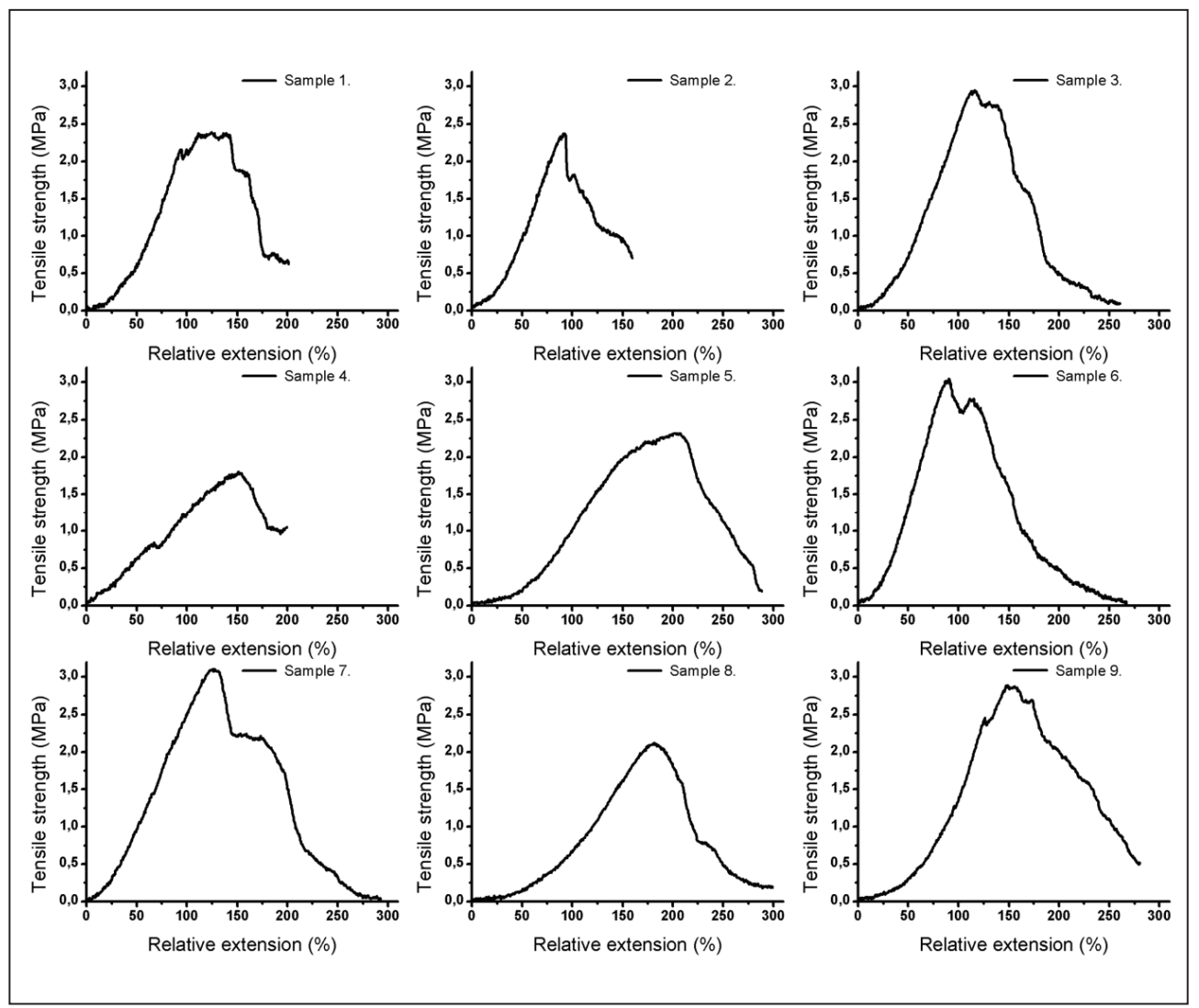

Figure 3. Tensile strength - Relative extension curves of longitudinal samples

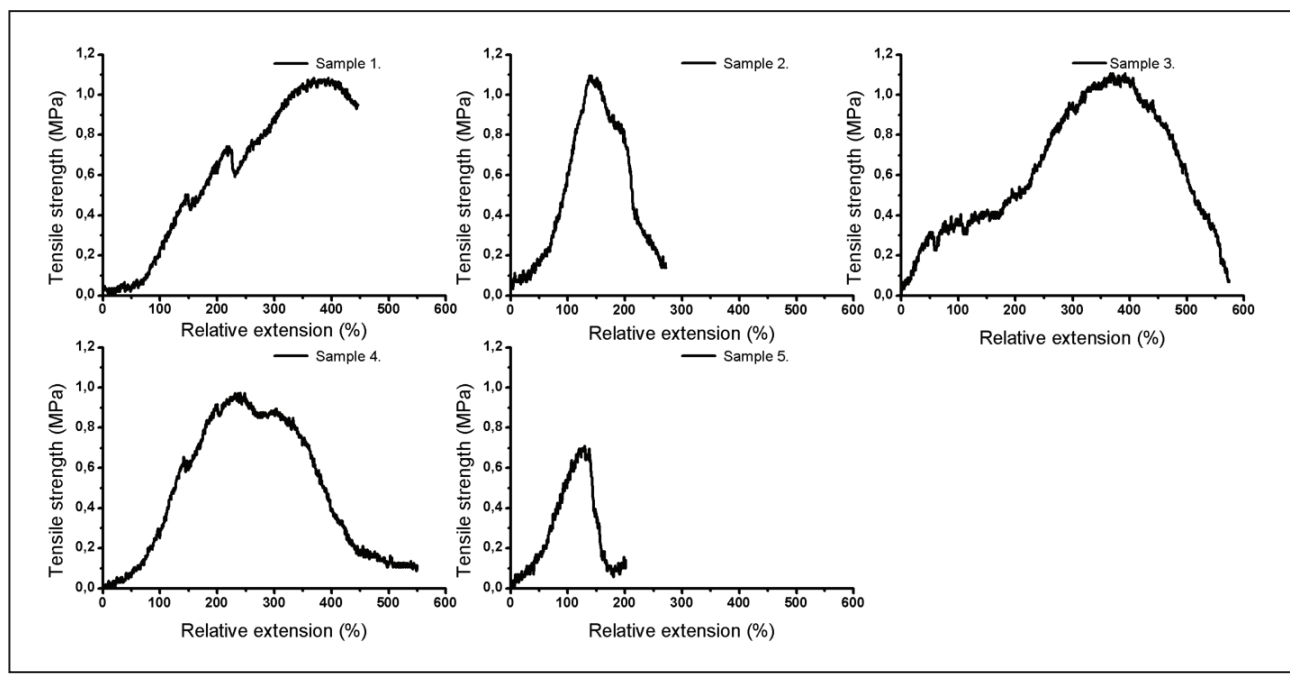

Figure 4. Tensile strength - Relative extension curves of transversal samples 


\begin{tabular}{|c|c|c|c|c|c|c|}
\hline \multirow[b]{2}{*}{ Sample } & \multicolumn{3}{|c|}{ Transversal samples } & \multicolumn{3}{|c|}{ Longitudinal samples } \\
\hline & $\begin{array}{c}\text { Relative } \\
\text { extension } \\
\varepsilon_{\mathrm{t}}(\%)\end{array}$ & $\begin{array}{c}\text { Tensile } \\
\text { strength } \\
\sigma_{t}(\mathrm{MPa})\end{array}$ & $\begin{array}{c}\text { Elastic } \\
\text { modulus } \\
\mathrm{E}_{\mathrm{t}}(\mathrm{MPa})\end{array}$ & $\begin{array}{c}\text { Relative } \\
\text { extension } \\
\varepsilon_{t}(\%)\end{array}$ & $\begin{array}{c}\text { Tensile } \\
\text { strength } \\
\sigma_{t}(\mathrm{MPa})\end{array}$ & $\begin{array}{c}\text { Elastic } \\
\text { modulus } \\
\mathrm{E}_{\mathrm{t}}(\mathrm{MPa})\end{array}$ \\
\hline 1 & 372 & 1.09 & 0.29 & 125 & 2.39 & 1.91 \\
\hline 2 & 141 & 1.10 & 0.78 & 92 & 2.37 & 2.56 \\
\hline 3 & 368 & 1.11 & 0.30 & 117 & 2.97 & 2.54 \\
\hline 4 & 232 & 0.97 & 0.42 & 152 & 1.80 & 1.18 \\
\hline 5 & 130 & 0.71 & 0.55 & 201 & 2.32 & 1.15 \\
\hline 6 & - & - & - & 91 & 3.05 & 3.33 \\
\hline 7 & - & - & - & 127 & 3.11 & 2.45 \\
\hline 8 & - & - & - & 182 & 2.12 & 1.17 \\
\hline 9 & - & - & - & 147 & 2.89 & 1.96 \\
\hline Mean \pm CI & $248 \pm 138$ & $0.99 \pm 0.19$ & $0.47 \pm 0.30$ & $137 \pm 31$ & $2.55 \pm 0.38$ & $2.03 \pm 0.64$ \\
\hline
\end{tabular}

Table 3. The calculated mechanical properties of coronary veins

ples. The averages and the standard deviations of the mechanical properties were calculated for the two directions. First of all the relative extension was almost twice higher for the transversal direction.

The tensile strength of the transversal sample was less than half of the longitudinal sample and the Young's modulus was almost the quarter of the longitudinal direction.

In order to have the visual comparison between the two directions, one longitudinal and one transversal curves were chosen closest to the average of the calculated mechanical properties. Finally the sample 4. of transversal direction and the sample 9. of longitudinal direction were compared in one diagram (Figure 5).

Based on the comparison it was obvious that the longitudinal samples need higher force to tear than the transversal, but they had worse relative extension and worse elongation properties. There is another important issue, the question of damage. The longitudinal samples after the maximal loading had a fast dive and complete rupture, but the transversal samples had a plateau phase and kept the strength after

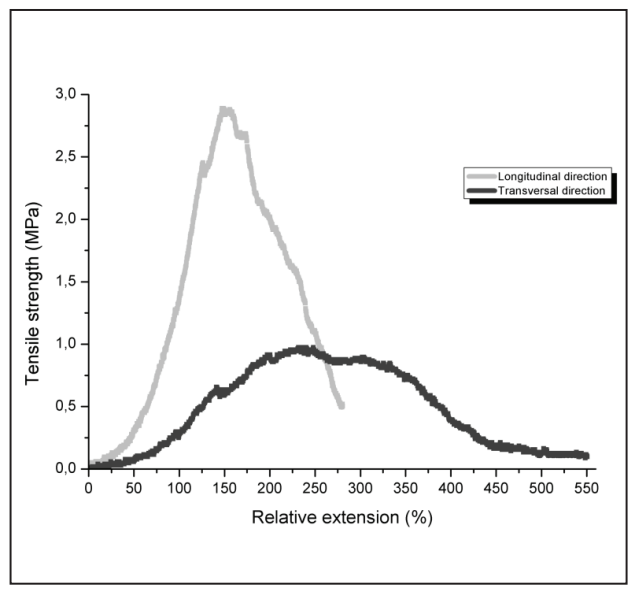

Figure 5. Comparison of the longitudinal sample and transversal sample characteristic

the injury and the maximal strength were reached. The curve was much flatter and extended in case of the transversal sample than the longitudinal.

\section{Conclusions}

The results obviously prove the mechanical differences between the longitudinal and transversal properties of the coronary veins. These are important parameters, because in 
case of special application the maximal elongation capability and the maximal force that the vein can tolerate without injury had to be known.

The mechanical properties of the coronary veins were tested and defined however there are still some questions. The elastic phase is the zone wherein the veins don't have any kind of injury and if the loadings stopped the vein retakes again it's original size. However it is not known whether the veins are able to reshape after loading or they remain in the extended size reached by testing. The individ- ual role of the different layers of coronary veins is not known during the mechanical testing. These questions should be investigated in order to have a complete analysis of the mechanical properties of the coronary veins.

\section{Conflict on interest statement}

We wish to confirm that there are no known conflicts of interest associated with this publication and there has been no significant financial support for this work that could have influenced its outcome.

\section{REFERENCES}

1. Balázs T, Bognár E, Zima E, Dobránszky J. 2008. Mechanical Properties of Coronary Veins. Gépészet 2008, Proceedings of Sixth Conference on Mechanical Engineering, n7.pdf.

2. Holzapfel GA, Gasser TC, Ogden RW. 2000. A new constitutive framework for arterial wall mechanics and a comparative study of material models. Journal of Elasticity, 61:1-48.

3. Holzapfel GA, Gasser TC, Stadler M. 2002. A structural model for the viscoelastic behaviour of arterial walls: continuum formulation and finite element analysis. European Journal of Mechanics A/Solids, 21:441-463.

4. Matsumoto T, Sato M. 2002. Analysis of stress and strain distribution in the artery wall consisted of layers with different elastic modulus and opening angle. JSME International Journal Series C, Mechanical Systems, Machine Elements Manufacturing, 45:906-912.

5. Xiao L, Aditya P, Ghassam SK. 2004. Biaxial incremental homeostatic elastic moduli of coronary artery: two layer model. American Journal of Physiology, Heart and Circulatory Physiology, 287:H1663-H1669.
6. Fung YC, Liu SQ. 1995. Determination of the Mechanical Properties of the Different layers of Blood Vessels in vivo. Proceedings of the National Academy of Sciences of the United States of America, 92:2169-2173.

7. Monos E, Berczi V, Nádasy Gy. 1995. Local controls of veins: biomechanical, metabolic, and humoral aspects. Physiological reviews.

8. Jenny S, Ghassam SK. 2006. A novel strategy for increasing wall thickness of coronary venules prior to retroperfusion. American Journal of Physiology, Heart and Circulatory Physiology, 291:H972-H978.

9. Molnár F, Till S, Halász G. 2005. Arterial blood flow and blood pressure measurements at a physical model of human arterial system. Embec 2005, 3rd Europian Medical \& Biological Engineering Conference, ISSN 1727-1983.

10. Till S, Halász G. 2004. The effect of different artery wall models on arterial blood flow simulation. Proceedings of the first conference on biomechanics, Budapest, Hungary, page 480485. 
11. Till S, Halász G. 2004. Modelling and numerical computation of arterial blood flow. Proceedings of the 4. conference on mechanical engineering, Budapest, Hungary, Volume 2, page 769-773.

12. Bartels-Stringer M, Terlunen L, Siero H, Russel FG, Smits P, Kramers C. 2004. Preserved vascu- lar reactivity of rat renal arteries after cold storage. Cryobiology, 48(1):95-8.

13. Boerboom LE, Wooldridge TA, Olinger GN, Rusch NJ. 1992. Effects of storage solutions on contraction and relaxation of isolated saphenous veins. J Cardiovasc Pharmacol, 20 Suppl $12: S 80-4$.

\section{Tibor Balázs}

Budapest University of Technology and Economics Department of Materials Science and Engineering H-1111 Budapest, Bertalan Lajos 7. MT.

Tel.: (+36) 30 420-2643

Fax: (+36) 1326-4945 